\title{
The Maturity of a Budgeting System and its Influence on Corporate Performance
}

\author{
Boris Popesko, Petr Novák, Ján Dvorský, Šárka Papadaki
}

Tomas Bata University in Zlín, nám T. G. Masaryka 5555, 76001 Zlín, Czech

Republic,popesko@fame.utb.cz

\begin{abstract}
In recent decades, the features making up corporate budgeting systems have been profoundly deliberated over by academics and professionals. Indeed, so-called traditional methods of budgeting have borne the brunt of severe criticism due to their inflexibility and the sheer amount of time they demand of employees. Nonetheless, several examples exist of budgeting systems that have somehow been transformed, and of organizations which have adopted advanced, flexible budgeting procedures based on evaluation of performance. In the study presented, the authors look into any relationships that may exist between the primary elements of corporate budgeting systems and their performance in the enterprise. The aim is to contribute towards existing knowledge by: 1) summarizing the latest advances that relate to budgeting and corporate performance; 2) reporting on current budgeting practices applied by companies in the Czech Republic, with analysis of how budgeting systems affect managerial behaviour; 3) evaluating any statistical dependence between selected features of corporate budgeting systems; i.e. utilizing a budget as a managerial tool, how enterprises express the added value of budgeting systems, endeavour on the part of management in implementing an effective budgeting system, the workload pertaining to individual components of a budgeting system, and the significance of a budgeting system in comparison with other tools designed for adapting to change in market conditions. In general, the study describes interconnections between the profit-based performance of firms and the majority of the factors and features of the budgeting systems examined.
\end{abstract}

Keywords: Budgeting; Corporate Performance; Beyond Budgeting

\section{Introduction}

Budgeting, one of the essential tools of management accounting, is frequently used for control of organizations by management [16]. Malmi et al. [22] states that budgeting is one of the main tasks of a firm's accountants. Traditional budgets are usually based on annual periods and present the transformation of a plan into currency units [10].

Over the last three decades, it has been possible to observe increasing dissatisfaction with traditional budgeting systems: they began to be frequently 
criticised in literature and by practitioners. Bunce et al. [7] presented a number of shortcomings of budgeting, including such claims as the following: that annual budgeting is soon outdated; is time-consuming, expensive and causes gaming; does not add value; and is based on a supply-oriented idea of production, which means that it lacks a customer orientation. These statements are supported by other authors: Libby and Lindsay [19] state that budgets are criticized for being time-consuming. Prendergast [27] claims that a lot of guesswork is required in the budgeting process, which takes up a lot of managerial time. Similarly, Neely et al. [25], state that the budgeting process actually consumes up to $20 \%$ of all managerial time. Nazli Nik Ahmad et al. [24] argue that budgets do not take into account the aspects of customers and quality, and thus prove ineffective in a changing environment.

In literature we can observe the broad discussion related to the elimination of the above-stated limitations of traditional budgets. Henttu-Aho and Järvinen [16] describe this discussion as the Beyond Budgeting debate. Scientific studies presented in recent decades reflect this normative criticism of the changing budgeting practice: they conclude that some shift exists from annual budgeting practices towards methods of simplified budgeting and rolling forecasts with a more forward-looking emphasis [19, 20, 26, 31]. However, only limited evidence exists of radical developments, or of companies that have applied Beyond Budgeting. A simple explanation of this is the fact that most transformations of budgeting practices or systems are both continuous and incremental, and they take place over relatively long periods of time [16]. In a study published in 2015, we have observed a very low number of firms which plan to abandon the traditional use of budgets for control but a modest number of firms which plan some changes in the budegting process [28].

In general, budgeting practices are changing very slowly [11]. In a few field studies, traditional budgeting still seems to be in a relatively strong position, but some evidence exists of emerging developments such as rolling forecasts and the balanced scorecard $[19,34]$.

Hansen et al. [14] state that dissatisfaction with budgeting systems is leading to two different approaches: some firms wish remove budgeting altogether and others wish to improve it. Hope and Fraser [17] present several studies of European companies which abandoned traditional budgeting systems and replaced it with performance measurement systems based on performance indicators.

Classical management accounting textbooks [10] point at the conflicts in utilization of budgets; this is caused by utilizing the self-same budgeting system for different purposes such as motivation and planning. This conflict causes unfavourable manager behaviour which may in turn affect a decrease in company performance. Henttu-Aho and Järvinen [16] state that interaction between the multiple purposes and goals of budgeting could be regarded as the central theme in budgeting studies. Arnolda and Gillenkirch [2] presented a deep study focusing 
on analysis of the conflict between different roles of the budget. The authors also state that conflict between different budgetary purposes has been analysed from an economic perspective, but little is known about their effects on corporate behaviour beyond monetary incentives.

A frequently criticised attribute of traditional short-term budgeting is its strict orientation on annual accounting periods [1]. One of the trends present in contemporary budgeting practices is the use of rolling budgets or rolling forecasts. These are produced by firms on a monthly or quarterly basis, and illustrate more dynamic and flexible processes in contrast to static traditional budgeting [16]. In rolling forecasts, the forecast is usually prepared for a specified future period (usually between 12 and 18 months) and adds a new month or quarter as the old month or quarter ends. The rolling forecast includes several benefits such as continuous planning throughout the year, less detailed content, easier updating, better focus on the future and timely reaction to planning [15].

In the literature, we also observe indications of gradual fragmentation of budgeting into various budget-related management accounting methods. These include fixed cost budgeting, activity-based budgeting, rolling budgets, rolling forecasts, the economic value added, target setting, balanced scorecard and benchmarking [16, 29, 34].

One of the most crucial features of modern budgeting practices is its linkage to company performance. Performance-based indicators are a key building block of the Beyond Budgeting approach [17]. The relation between budgeting systems and performance is usually explained through budgetary participation [33]. The relationship between budgetary participation and corporate performance has been investigated by many studies [3, 4, 5, 12, 21, 32]. Yang Qi [33] defines two major conceptual models in current management accounting literature which link budgetary participation with performance. The first are psychological theories [23] which state that participation (the upward information sharing) in the budgeting process - when given to subordinates - can stimulate motivation and commitment in budget-setting; this in turn positively affects job satisfaction and performance $[6,8,18]$. The second model explains the above-stated relationship from a cognitive point of view. It is explained that through budget participation (the downward information sharing), subordinates gain information from superiors that helps clarify their organizational roles, including their duties, responsibilities and expected performance; all of this leads to a performance increase $[9,18,30]$.

In our study, we have focused on the relationship between the budgeting system maturity, which is measured by quality perception of managers and perceived company performance. We expected that firms with more advanced budgeting systems demonstrate higher performance when compared with their competitors. The maturity of the budgeting system has been measured by four factors based on the Libby and Lindsay [19] study, in which these factors were analysed as the important indicators of the budgeting system. We have analysed the following 
factors: UB, the use of budgets for control where we have analysed on which level firms are using them in that capacity; PAV, the perception of the budgeting system's added value, where we have measured how firms perceive the overall value-added quality of the budgeting system; EMNA, an effort dedicated to the budget's preparation; and ERP, the effectiveness of the budgeting process in the field of adaptation to changes in the business environment.

This paper tries to contribute to the recent discussion in investigating the relationship between company performance and selected factors of the organizational budgeting process. Despite the several limitations of the study (the subjectivness of the data collected from respondents and statistical processing of that data), we hope it brings new findings related to budgeting and its use in Czech firms.

\section{Methods}

The main objective of this paper is to identify and quantify significant factors determining profit-based performance of enterprises in the Czech Republic. The secondary objective is to compare profit-based performances of enterprises among selected groups of enterprises. The statistical characteristics of enterprises are investigated both by the number of employees and by the volume of sales received over the two preceding years. Scientific hypotheses have been formulated to fulfil the main and secondary objective of this paper.

$\mathrm{H} 1$ : Enterprise performance in terms of profit (EP) is determined by the following factors: a) use of budget (UB) as a tool for enterprise management, b) perception of added value of the budgeting system for an enterprise (PAV), c) effort on the part of managers and workload volume expended to compose a budget (EMNA), d) significance of the budgeting process compared with other tools to adapt to changing market conditions (BP).

H2A: None of the selected groups of enterprises - neither by the number of employees nor by the volume of sales - report any statistically significant differences in the overall structure of evaluation of enterprise performance with regard to their direct competitors.

H2B: Enterprises under and above 500 employees and enterprises with sales under and above 8 million EUR will report statistically significant differences in their enterprise's evaluation of performance (in terms of profit) with regard to their direct competitors.

The research was undertaken in 2015 by the authors, these being academics at the Faculty of Management and Economics of the Tomas Bata University in Zlin (UTB). Data was collected via a questionnaire accessible on-line. Initially, the 
ALBERTINA database was utilized to discern which enterprises would make suitable subjects for investigation, as well as to access contact details for the responsible persons at the same. The authors narrowed their search to companies of medium and large size operating in the industrial sector, thereby excluding service and trade establishments. The authors expected that such enterprises would represent those wherein budgeting played a critical role. For inclusion in the sample, the individuals contacted had to be employed at a senior level of financial management, with corresponding job titles such as Financial Director, Chief Financial Officer, Economic Director or Head of the Controlling Department. Such criteria were important in order to ensure that the contacts would possess sufficient experience in activities related to budgeting and gauging performance.

Afterwards, the people detailed in the database were contacted by telephone and asked about their willingness to take part in the study. Those who agreed to be surveyed were sent an email containing a link to the questionnaire, the latter taking approximately 30 minutes to complete.

In all, the authors contacted 1,375 companies, out of which 618 agreed to participate in the survey. In the end, the authors received 177 fully complete questionnaires, i.e. a return rate of $12.9 \%$.

We applied regressive analysis in order to fulfil the main objective. The significance of the linear regressive model was to provide explanation of the course of dependency (relation) between enterprise performance (dependent variable) and its determinants (independent variables - UB, PAV, EMNA, BP). We verified the assumption of linearity through a graphic analysis of data with the application of dot graphs (Scatter Plots), of which significance consists of finding non-linear patterns between a dependent variable and independent variable. We performed the assumption of normal distribution of data with comparison of graphic analysis with the application of a histogram with a normal distribution curve (curve of normal profitability plot for every independent variable) and with testing of descriptive characteristics of independent variables (z-test of skewness and acuteness). The critical value of inclusion of independent variables into the regressive model is 1.973 (173 degrees of freedom, significance level at 0.05 ). The assumption of constant scattering of random errors and thereby also residues (homoscedasticity) was tested through Bartlett's test. The assumption of homoscedasticity was satisfied if the p-value of the test was greater than 0.05 . We used the comparison matrix to determine the intensity of dependency of a dependent variable on independent variables. Values of parameters of the linear regressive model with more independent variables can be affected negatively with multicollinearity. We accept these multicollinearities in the results of the regressive modelling if the value of Variance Inflation Factor is more than 5 [13].

We applied z-score to determine differences between individual permutations of a statistical attribute. In order to verify dependency between two statistical attributes, we used the Chi-square test of independence in the contingency table, 
based on calculation of square contingency. The execution of the independence test is conditional on that none of the theoretical frequencies is less than 1 and that a maximum of $20 \%$ of theoretical frequencies are less than 5 [13]. We utilized Pearson's contingency coefficient to determine the value of dependence. We selected the significance level at 5\% (0.05) for all performed tests. Graphic verifying of assumptions as well as testing were performed in the statistics software of data analysing IBM SPSS statistics.

The basic regressive model with linear function is defined with the following relation between the dependent variable (EP) and independent variables (UB, PAV, EMNA, BP):

$E P=\beta_{0}+\beta_{U B} x U B+\beta_{P A V} x P A V+\beta_{E M N A} x$ EMNA $+\beta_{B P} x B P$,

where $U B$ - independent variable; $\beta_{0}$ - constant, $\beta_{U B ;} \beta_{P A V} \beta_{E M N A ;} \beta_{B P}$ - parameters of independent variables (UB, PAV, EMNA, BP); UB, PAV, EMNA, BP - independent variables.

For purposes of evaluation of the regressive model proposed in this manner, it was necessary to unify scale of determinants evaluation into a uniform structure. After consulting with experts, we have assigned word equivalents to the initial numeric evaluation of determinants PAV (perceived value on the scale 0-100): 0-20 significantly lower, 20-40 slightly lower, 40-60 on the same level, 60-80 slightly greater and 80-100 significantly greater. Further, for the factor affecting EMNA (rating 1 -5), we have the scale: 1 - significantly lower, 2 - slightly lower, 3 - on the same level, 4 - slightly greater and 5 - significantly greater.

Basic results of the descriptive statistics of enterprises by selected statistical attributes (Table 1):

Table1

Detailed statistics for respondents of the survey

\begin{tabular}{|l|c|c|}
\hline & Frequencies & $\%$ \\
\hline Number of employees & 145 & $81.9 \%$ \\
\hline $100-500$ & 32 & $18.1 \%$ \\
\hline More than 500 & 81 & $45.7 \%$ \\
\hline Sector & 12 & $6.8 \%$ \\
\hline Manufacturing & 16 & $9 \%$ \\
\hline Automotive & 15 & $8.5 \%$ \\
\hline Construction & 15 & $8.5 \%$ \\
\hline Engineering & 38 & $21.5 \%$ \\
\hline Agriculture & 82 & $46.3 \%$ \\
\hline Other & 95 & $53.7 \%$ \\
\hline Annual Revenue & \multicolumn{2}{|l|}{} \\
\hline Less than 8 million EUR &
\end{tabular}




\section{Results and Discussion}

The selective data file consisted of 177 filled-in questionnaires from enterprises. With regard to fulfilment of the paper's objective and the verification of hypotheses, we identified the most significant determinants affecting enterprise performance. Variables derived from results of descriptive statistics (dependent, independent) with expression of absolute and relative frequency of enterprises on the rating scale are given in Table 2.

Table 2

Evaluation of enterprise performance and their determinants in terms of absolute and relative frequencies

\begin{tabular}{|c|c|c|c|c|c|}
\hline \multirow{2}{*}{$\begin{array}{c}\text { Dependent and } \\
\text { independent } \\
\text { variables }\end{array}$} & $\begin{array}{c}\text { Significantly } \\
\text { lower }\end{array}$ & $\begin{array}{c}\text { Slightly } \\
\text { lower }\end{array}$ & $\begin{array}{c}\text { On the } \\
\text { same } \\
\text { level }\end{array}$ & $\begin{array}{c}\text { Slightly } \\
\text { greater }\end{array}$ & $\begin{array}{c}\text { Significantly } \\
\text { greater }\end{array}$ \\
\cline { 2 - 6 } & 10 & 24 & 68 & 57 & 18 \\
\cline { 2 - 6 } EP & $5.6 \%$ & $13.6 \%$ & $38.4 \%$ & $32.2 \%$ & $10.2 \%$ \\
\hline \multirow{2}{*}{ UB } & 6 & 29 & 70 & 49 & 23 \\
\cline { 2 - 6 } & $3.4 \%$ & $16.4 \%$ & $39.5 \%$ & $27.7 \%$ & $13.0 \%$ \\
\hline \multirow{2}{*}{ PAV } & 4 & 1 & 25 & 63 & 84 \\
\cline { 2 - 6 } & $2.3 \%$ & $0.6 \%$ & $14.1 \%$ & $35.6 \%$ & $47.5 \%$ \\
\hline \multirow{2}{*}{ EMNA } & 32 & 53 & 49 & 25 & 18 \\
\hline \multirow{2}{*}{ BP } & 18.1 & 29.9 & 27.7 & 14.1 & 10.2 \\
\cline { 2 - 6 } & 26 & 33 & 89 & 29 & 0 \\
\hline
\end{tabular}

Results of relative and absolute frequencies show that more than $80 \%$ of respondents hold the opinion that performance of their enterprise (EP) is the same or greater compared with their direct competitors. Results also show that $47.5 \%$ of enterprises hold the opinion that their budgeting system has a significantly high added value (PAV) for their enterprise.

In order to verify assumptions of the regressive analysis, which are specified in greater detail in Methods, we used graphical data analysis. Linear courses between the enterprise performance (in terms of profit) and independent variables (UB, PAV, EMNA, BP) result from the graphic data visualization performed in the IBM SPSS statistics. The linearity assumption is satisfied. We can observe deviations in frequency of individual groups of enterprises from the normal distribution curve during visualization of the histogram of independent variable BP with the normal distribution curve. Subsequently we will proceed to calculations and testing of descriptive characteristics (skewness, kurtosis) from which we can decide whether data satisfy the condition of normal distribution. Results are illustrated in Table 3. 
Table 3

Skewness, kurtosis and z-value of independent variables of company performance model

\begin{tabular}{|c|c|c|c|c|c|}
\hline $\begin{array}{c}\text { Independent } \\
\text { variable }\end{array}$ & Skewness & $\begin{array}{c}\mathbf{Z} \text { - value } \\
\text { (skewness) }\end{array}$ & Kurtosis & $\begin{array}{c}\mathbf{Z} \text { - value } \\
\text { (kurtosis) }\end{array}$ & $\begin{array}{c}\text { Bartlett's } \\
\text { test }\end{array}$ \\
\hline UB & 0.987 & 0.425 & 1.081 & 0.556 & 0.706 \\
\hline PAV & 0.647 & 1.899 & 0.568 & 0.754 & 0.447 \\
\hline EMNA & 1.983 & 2.687 & 1.716 & 1.188 & 0.059 \\
\hline BP & 2.612 & 2.872 & -1.633 & -3.175 & $<0.010$ \\
\hline
\end{tabular}

Results confirmed that independent variables UB and PAV satisfied the assumption of rating frequency normal distribution (z- score skewness and $\mathrm{z}$ score kurtosis $\leq 2.000$ ) as well as assumption of homoscedasticity (Bartlett's test for UB and Istrie $\geq 1.899$ ). Independent variables EMNA and BP do not comply conditions of normal data distribution (EMNA: skewness z-score $=2.687$; BP: skewness and kurtosis $\mathrm{z}$-score > 2.000). The independent variable BP does not comply the condition of homoscedasticity (Bartlett's test $<0.01$ ). Thus, the efficiency of the "budgeting process at adapting to the changing market" (BP) cannot be considered as a significant factor which would affect company performance. We did not admit the independent variable EMNA as a significant determinant into the regressive model in the first step. However, error of the data normality assumption is shown as decreasing with sufficiently large file extent (177 enterprises) [13]. Results of t-value confirm the statistical significance of the EMNA ( $\mathrm{t}$-value $=3.174$ ) determinant, because it is greater than the critical area of its refusal. Intensity of dependency between a dependent variable and significant independent variables is displayed in Table 4.

Table 4

Correlation matrix of variables in company performance model

\begin{tabular}{|c|c|c|c|c|}
\hline & EP & UB & PAV & EMNA \\
\hline EP & 1 & & & \\
\hline UB & 0.6722 & 1 & & \\
\hline PAV & 0.58334 & 0.6461 & 1 & \\
\hline EMNA & 0.54125 & 0.4679 & 0.5674 & 1 \\
\hline
\end{tabular}

Medium-strong to strong dependency results from the correlation matrix results with the application of the correlation coefficient [13]. We admit independent variables UB, PAV and EMNA as statistically significant parameters of the linear regressive models from z-test results (see Table 3) and further EMNA results of t-test and correlation matrix (see Table 4). We have performed testing of the significance of the regression model proposed in this manner with three independent variables and recorded them into the following Table 5.

Analysis of the regression model by means of graphic and analytical tools has confirmed conditions of linearity, homoscedasticity and independence of variances as well as a condition of normality. 
Table 5

Characteristics of regression model of company performance

\begin{tabular}{|c|c|c|c|c|c|}
\hline \multicolumn{6}{|c|}{ Least squares multiple regression } \\
\hline \multicolumn{4}{|l|}{$\mathrm{R}^{2}$} & \multicolumn{2}{|c|}{0.52147} \\
\hline \multicolumn{4}{|l|}{ Adjusted $\mathrm{R}^{2}$} & \multicolumn{2}{|c|}{0.51317} \\
\hline \multicolumn{4}{|l|}{ Multiple correlation coefficient } & \multicolumn{2}{|c|}{0.72212} \\
\hline \multicolumn{4}{|l|}{ Residual standard deviation } & \multicolumn{2}{|c|}{0.1328} \\
\hline \multicolumn{6}{|c|}{ Regression equation } \\
\hline Independent variables & Coefficient & Std. Error & t-Stat & p-value & VIF \\
\hline Constant & 0.2156 & & & & \\
\hline UB & 0.4857 & 0.2074 & 2.3412 & 0.020 & 1.8241 \\
\hline PAV & 0.2821 & 0.0844 & 3.3424 & 0.001 & 1.5157 \\
\hline EMNA & 0.2981 & 0.1229 & 2.4255 & 0.016 & 2.8488 \\
\hline \multicolumn{6}{|c|}{ Analysis of variance } \\
\hline \multicolumn{4}{|c|}{ F-ratio } & \multicolumn{2}{|c|}{18.014} \\
\hline \multicolumn{4}{|c|}{ Significant level } & \multicolumn{2}{|c|}{$<0.001$} \\
\hline
\end{tabular}

Variance Inflation Factor results have not proved multicollinearity in the regression model (VIF - test of independent variables is less than critical value 5: $\mathrm{UB}=1.8241 ; \mathrm{PAV}=1.5157 ; \mathrm{DPP}=2.8488)$. Differences between the determination factor and adjusted coefficient of determination are minimal $\left(\mathrm{R}^{2}\right.$ 0.52147 and Adjusted $\left.\mathrm{R}^{2}-0.51317\right)$. P-value of F-ratio of the entire regression model is less than 0.001. Following the aforementioned conclusions (see Table 5), we proceed to the formulation of a regression equation with linear function; this acquires the form:

$E P=0.4857 \times U B+0.2821 \times P A V+0.2981 \times E M N A$,

where EP - enterprise performance (profit), UB - use of budget as a tool of enterprise management, PAV - perception of added value of the budgeting system for a company, EMNA - effort on the part of managers and quantity of their activities expended to compose a budget.

The proposed regression model is statistically significant with three factors on the level of significance 0.05 . The variability of the selected independent variables (UB, PAV, EMNA) explains up to $52.14 \%$ variability of enterprise performance, which can be considered as satisfactory. The other $47.86 \%$ of enterprise performance variability is explained by determinants not included in our search. Results show that UB determinant has the greatest influence on EP, or specifically that enterprises use a budget as a tool for enterprise management. Perception of added value of the budgeting system for an enterprise has the smallest influence out of the statistically significant determinants. Efficiency of the budgeting process at adapting to the changing market (BP) does not have any statistically significant influence and does not determine enterprise performance in terms of profit. H1 hypothesis can be admitted, however with the exclusion of BP determinant. 
We have investigated enterprise performance on a sample of 177 enterprises in terms of profit. The authors have identified four determinants which come not only from theoretical-professional knowledge but also from practical knowledge. These selected determinants were subjected to statistical evaluation. The achieved results can be seen as a tool to explain significance and importance of the selected determinants and their effect on enterprise performance.

Table 6 includes responses of respondents by selected groups who evaluated enterprise performance during the past two years, with respect to their direct competitors.

Table 6

Comparison of enterprise performance evaluation in relation to direct competitors

\begin{tabular}{|c|c|c|c|c|c|}
\hline \multirow{2}{*}{ Profit } & \multicolumn{2}{|c|}{$\begin{array}{c}\text { Number of } \\
\text { employees }\end{array}$} & \multicolumn{2}{|c|}{ Volume of sales } & Z - score \\
\cline { 2 - 6 } & $\mathbf{< 5 0 0}$ & $\mathbf{> 5 0 0}$ & $\begin{array}{c}<\mathbf{8} \\
\text { million } \\
\text { EUR }\end{array}$ & $\begin{array}{c}>\mathbf{8} \\
\text { million } \\
\text { EUR }\end{array}$ & $\begin{array}{l}\text { Number } \\
\text { employees } \\
\text { Volume of sales }\end{array}$ \\
\hline $\begin{array}{c}\text { Significantly greater than } \\
\text { competitors: } 10.2 \% \\
\text { enterprises }\end{array}$ & 16 & 2 & 12 & 6 & 0.417 \\
\cline { 2 - 7 } & $11 \%$ & $6 \%$ & $14.3 \%$ & $6.3 \%$ & 0.054 \\
\hline $\begin{array}{c}\text { Slightly greater than } \\
\text { competitors: } 32.2 \% \\
\text { enterprises }\end{array}$ & 50 & 7 & 24 & 33 & 0.167 \\
\cline { 2 - 7 } & $34 \%$ & $22 \%$ & $29.3 \%$ & $34.7 \%$ & 0.435 \\
\hline $\begin{array}{c}\text { On the same level: } 38.4 \% \\
\text { enterprises }\end{array}$ & 54 & 14 & 29 & 39 & 0.490 \\
\hline & $37 \%$ & $44 \%$ & $35.4 \%$ & $41.1 \%$ & 0.435 \\
\hline $\begin{array}{c}\text { Slightly lower than } \\
\text { competitors: } 12.6 \% \\
\text { enterprises }\end{array}$ & 19 & 5 & 12 & 12 & 0.703 \\
\cline { 2 - 7 } & $13 \%$ & $16 \%$ & $14.6 \%$ & $12.6 \%$ & 0.696 \\
\hline $\begin{array}{c}\text { Significantly lower than } \\
\text { competitors: } 5.3 \% \\
\text { enterprises }\end{array}$ & 6 & 4 & 5 & 5 & 0.064 \\
\cline { 2 - 6 } & $4 \%$ & $13 \%$ & $6.1 \%$ & $5.3 \%$ & 0.810 \\
\hline Chi - square & 7.200 & \multicolumn{2}{|c|}{4.000} & \\
\hline P - value & \multicolumn{2}{|c|}{0.124} & \multicolumn{2}{|c|}{0.412} & \\
\hline
\end{tabular}

Results (see table 6) show that up to $42.4 \%$ of respondents evaluate the performance level of their enterprise (by profit) better (significantly and slightly greater) than their direct competitor for the past two years. Structure of enterprise evaluation by number of employees or by volume of sales is not statistically significant ( $\mathrm{p}$-value is greater than 0.05). And thus we accept the H2A hypothesis. Z-score results show that differences in the number of employees up to 500 and above 500 and also with the volume of sales under 8 million EUR and above 8 million EUR do not represent statistically significant differences in the frequency of responses ( $p$-value > 0.05). And thus we refuse the H2B hypothesis. 


\section{Discussion and conclusions}

Despite criticism of the traditional budgeting systems which has appeared plentifully in recent literature, we can state that budgeting represents an irreplaceable tool in enterprises and plays a significant role also in terms of enterprise performance. This fact was confirmed by the survey performed. As the statistical linear regression model results show, we are able to identify determinants which are perceived in companies as significant with respect to increase in the enterprise performance.

We perceive in our case the following factors as determinants with significant influence in companies:

- use of budget (UB) as a tool for enterprise management,

- perception of added value of the budgeting system for an enterprise (PAV),

- effort on the part of managers and quantity of activities to compose a budget (EMNA).

On the contrary, the factor of significance of the "budgeting process compared to other tools for adapting to changing market conditions" (BP) appeared to be statistically insignificant this means that managers do not perceive for it any significant influence on enterprise performance in terms of profit. We can derive from it that managers perceive the significance of the budgeting process itself (with regard to influence on enterprise performance) on the same level as application of other relevant tools.

We can formulate a number of conclusions on the basis of the evaluation of these factors. The use of a budget as a tool of management has a statistical dependence on perceived enterprise performance in terms of profit. This conclusion is in partial conflict with opinion of some authors [19]. They perceive enterprises which stopped using a budget for management purposes as those using more developed systems for performance control. This conclusion can be also interpreted in the manner that there is a significant group of enterprises in our sample which do not use budgeting at all (or possibly only for simplified purposes, as for example for resource allocation).

Another factor for which statistical dependency appeared is the perception of added value of the budgeting system for an enterprise (PAV) to increase its performance. Results show that if a company perceives highly added value of its budgeting system, it is reflected into higher perceived value of enterprise performance. This dependency would confirm the assumption that more developed budgeting systems manifest themselves in higher perceived company performance.

Other factors which were investigated in relation to enterprise performance (EP) include "effort on the part of managers and number of activities expended to 
compose a budget" (EMNA). Results have confirmed that the greater effort expended to compose a budget can be demonstrated in a higher perceived value of performance. This fact would indicate that higher effort expended to budgeting is an attribute of a greater advanced level and quality of budget, which is then demonstrated in greater perceived enterprise performance, which according to searches of the literature is not a generally accepted fact.

\section{Acknowledgement}

This paper is one of the research outputs of the project GA 17-13518S/P403 "Determinants of budgeting and performance measurement systems design and impact of these systems on organizational behavior and organizational performance" registered at the Czech Science Foundation.

\section{References}

[1] Anthony, R. N. and Govindarajan, V.: Management Control Systems, Chicago, IL: Irwin, 1995

[2] Arnolda, M. C., Gillenkirch, R. M.: Using negotiated budgets for planning and performance evaluation: An experimental study, Accounting, Organizations and Society, Vol. 43, 2015, pp 1-16

[3] Becker, S. W., \& Green, D.: Budgeting and Employee Behavior, Journal of Business, Vol. 35, 1962, pp. 392-402

[4] Birnberg, J. G., \& Shields, J. F.: Three Decades of Behavioral Research: A Search for Order, Behavioral Research in Accounting, Vol. 1, 1989, pp. 2374

[5] Brownell, P.: Participation in Budgeting, Locus of Control and Organizational Effectiveness, The Accounting Review, Vol. 56(4), 1981, pp. $844-860$

[6] Brownell, P., \& McInnes, M.: Budgetary Participation, Motivation, and Managerial Performance Accounting Review, Vol. 61(4), 1986, pp. 587600

[7] Bunce, P., Fraser, R. and Woodcock, L.: Advanced budgeting: a journey to advanced management systems, Management Accounting Research, Vol. 6(3), 1995, pp. 253-265

[8] Chenhall, R., \& Brownell, P.: The Effect of Participative Budgeting on Job Satisfaction and Performance: Role Ambiguity As an Intervening Variable, Accounting, Organizations \& Society, Vol. 13(3), 1988, pp. 225-234

[9] Chong, V. K., Chong, K. M.: Budget Goal Commitment and Informational Effects of Budget Participation on Performance: A Structural Equation Modeling Approach. Behavioral Research in Accounting, Vol. 14, 2002, pp. $65-86$

[10] Drury, C.: Management \& Cost Accounting. London: Thomson, 2000 
[11] Granlund, M.: Towards explaining stability in and around management accounting systems, Management Accounting Research, Vol. 12(2), 2001, pp. $141-166$

[12] Gul, F. A., Tusi, Judy S. L., Fong, Steve C. C., Kwok, Helen Y. L.: Decentralization as a Moderating Factor in the Budgetary Participationperformance Relationship: Some Hong Kong Evidence, Accounting and Business Research, Vol. 25(98), 1995, pp. 107-113

[13] Hair, J. F.: Multivariate data analysis. Upper Saddle River: Prentice-Hall, 2010

[14] Hansen, S. C., Otley, D. T., Van der Stede, W. A.: Practice developments in budgeting: An overview and research perspective, Journal of Management Accounting Research, Vol. 15, 2003, pp. 95-116

[15] Hansen, S. C.: A theoretical analysis of the impact of adopting rolling budgets, activity-based budgeting and beyond budgeting, European Accounting Review, Vol. 20(2), 2010, pp. 289-319

[16] Henttu-Aho, T.: Enabling characteristics of new budgeting practice and the role of controller, Qualitative Research in Accounting \& Management, Vol. 13 (1), 2016, pp. 31-56

[17] Hope, J., Fraser, R.: Beyond Budgeting: How Managers Can Break Free from the Annual Performance Trap. Boston, Mass.: Harvard Business School Press, 2003

[18] Kren, L.: Budgetary Participation and Managerial Performance: The Impact of Information and Environmental Volatility, Accounting Review, Vol. 67 (3), 1992, pp. 511-526

[19] Libby, T., Lindsay, R. M.: Beyond budgeting or budgeting reconsidered? A survey of North-American budgeting practice, Management Accounting Research, Vol. 21(1), 2010, pp. 56-57

[20] Havierniková, K., Okręglicka, M., Lemańska-Majdzik, A.: Cluster cooperation and risk level in small and medium-sized enterprises, Polish Journal of Management Studies, Volume 14 (2), 2016, pp. 82-92

[21] Magner, N., Welker, R. B., Campbell, T. L.: The Interactive Effect of Budgetary Participation and Budget Favorability on Attitudes toward Budgetary Decision Makers: A Research Note. Accounting, Organizations \& Society, Vol. 20(7/8), 1995, pp. 611-618

[22] Malmi, T., Seppälä, T. and Rantanen, M.: The practice of management accounting in Finland - a change? The Finnish Journal of Business Economics, Vol. 50(4), 2001, pp. 480-501

[23] Murry, D.: The Performance Effects of Participative Budgeting: An Integration of Intervening and Moderating Variables. Behavioral Research in Accounting, Vol. 2(2), 1990, pp. 104-123 
[24] Nazli Nik Ahmad, N., Sulaiman, M., Alwi, N. M.: Are budgets useful? A survey of Malaysian companies, Managerial Auditing Journal, Vol. 18 (9), 2003, pp. 717-724

[25] Neely, A., Bourne, M., Adams, C.: Better budgeting or beyond budgeting?, Measuring Business Excellence, Vol. 7 (3), 2003, pp. 22-28

[26] Østergren, K. and Stensaker, I.: Management control without budgets: a field study of 'beyond budgeting' in practice, European Accounting Review, Vol. 20(1), 2011, pp. 149-181

[27] Prendergast, P.: Budgets hit back, Management Accounting, London, Vol. 78(1), 2000, pp. 14-17

[28] Popesko, B., Novák, P., Papadaki, Š., Hrabec, D., Are the Traditional Budgets Still Prevalent? Survey of the Czech Firms Budgeting Practices, Transformations in Business \& Economics, Vol. 14 (3C), 2015, pp. 373388

[29] Sandalgaard, N.: Uncertainty and budgets: an empirical investigation, Baltic Journal of Management, Vol. 7(4), 2012, pp. 397-415

[30] Shields, M. D and Young, S. M.: Antecedents and Consequences of Participative Budgeting: Evidence on the Effects of Asymmetrical Information, Journal of Management Accounting Research, Vol. 5, 1993, pp. $265-280$

[31] Sivabalan, P., Booth, P., Malmi, T. and Brown, D. A.: An exploratory study of operational reasons to budget, Accounting and Finance, Vol. 49(4), 2009, pp. 849-871

[32] Tsui, J. L.: The Impact of Culture on the Relationship between Budgetary Participation, Management Accounting Systems, and Managerial Performance: An Analysis of Chinese and Western Managers The International Journal of Accounting, Vol. 36(2), 2001, pp. 125-146

[33] Yang, Qi.: The Impact of the Budgeting Process on Performance in Small and Medium-Sized Firms in China, dissertation thesis, University of Twente, 2010, ISBN: 978-90-365-2983-9

[34] Ekholm, B. G., Wallin, J.: Is the annual budget really dead? The European Accounting Review, Vol. 9 (4), 2000, pp. 519-539 